Call of the wild
Bonobo research
threatened by civil
war in Congo
$p 262$

\title{
Europe agrees to boost Internet networks used by researchers
}

Declan Butler

The 15 member states of the European Union have approved an 80 million euro (US\$73 million) upgrade of Europe's research Internet networks. The move will provide the infrastructure needed to begin work on the concept of an advanced research computing 'grid'.

A bid for preparatory work on a research grid was submitted to the European Commission last week by the coordinator, the European Laboratory for Particle Physics (CERN), with five other national partners, including France's National Centre for Scientific Research (CNRS), Britain's Particle Physics and Astronomy Research Council (PPARC), and Italy's National Institute for Research in Nuclear and Subnuclear Physics (INFN), along with 15 other associate organizations, including IBM. EU investment is likely to be announced at a summit of politicalleaders in Lisbon next month.

The call for a proposal - unusual in that it asks for a single application from the European research community - represents a green light for the Géant project. This has been proposed by Dante, the Cambridgebased coordinator of 31 national research networks in Europe, as the successor to the current Ten-155 European research network.

Géant would boost the network's capacity from an average of 155 megabits per second to 2.5 gigabits per second this year, and to 10 gigabits per second and higher within four years. Member states fund the pan-European research network jointly, so the upgrade "will happen fast and be focused," says one commission official in Brussels.

The new commission funding stipulates that the network must operate at the same speed throughout Europe, even in poorer countries. "There is a need to avoid partitioning the European research infrastructure fabric and weakening European integration," says one commission document.

Dai Davies, general manager of Dante, is optimistic that this requirement can be met. "While national infrastructures are not of the same quality, this can be offset somewhat by balancing costs so that a part of the total are shared irrespective of geography," he says.

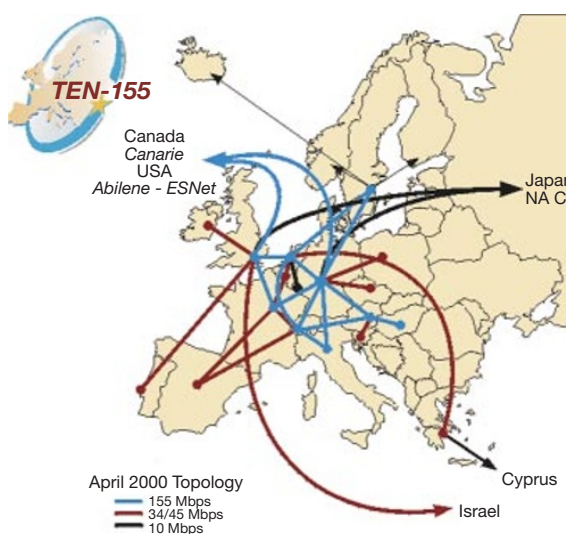

Ten-155: the current European research network.

Further support for research computing infrastructure may come from the Lisbon summit, which is likely to approve a broad commission proposal to boost the knowledge-based economy known as eEurope.

One commission official says that eEurope will extend Géant by organizing gigabit-persecond connections to the network from all campuses and research institutes in Europe. "The objective is to build a completely optical network throughout all Europe, including poorer countries, before 2005."
EU funding is likely to be of the order of 100 million euros. The overall cost could be over 1 billion euros, and would require national and regional agreement. The European Investment Bank - an autonomous body set up to further European integration by promoting EU economic policies - is said to be interested. The EU is likely to approve spending a further 50 million euros to build fast connections linking Géant to networks across the world.

Liberalization of EU telecommunications markets has prompted a 20 -fold reduction in costs over the past two years, according to Davies. He adds that progress in extending into central and eastern Europe has been easier than in Portugal and Greece, where telecommunications operators are reluctant to abandon monopolistic tendencies.

The quality of infrastructure now in sight means Europe can start work on a more advanced notion of research computing, the so-called 'grid'. The idea is that scientists would plug into the network and immediately have at their disposal the entire processing resources of the network.

The term 'grid' comes from the analogy with the electricity grid, where one can plug in an appliance and the power needed is

\section{A first Royal Society honour}

Sir John Maddox (right), editor of Nature for almost 23 years before his retirement in 1996, was last week elected the first

honorary fellow of Britain's Royal Society in London.

The position was introduced three years ago, and is intended to recognize individuals "who have rendered signal service to the cause of science, or whose election would significantly benefit the society by their great experience in other walks of life".

Maddox, a theoretical physicist by training, said on Monday that he was "delighted" at his election. "One can ask, is

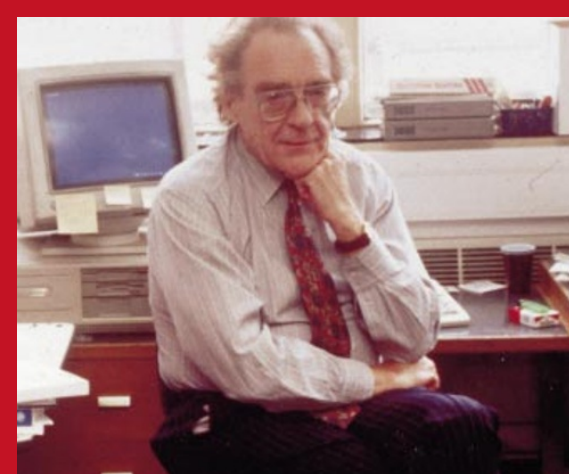

this gamekeeper turned poacher, or poacher turned gamekeeper?" he quipped. 
- always there. The complex handling of data and jobs between centres would be hidden from the end user by a new generation of software known as 'middleware'.

CERN's $\$ 1.8$ billion Large Hadron Collider (LHC) is an ideal test bed for the grid, as it will generate 7 petabytes $\left(10^{15}\right.$ bytes) of data every year when it comes online in 2005 . This information - requiring a thousand times more computing power than CERN can currently deliver - must be delivered to thousands of users in more than 40 countries. Using the grid concept, the Internet would function like a single computer and database rolled into one (see Nature 404, 213; 2000).

Political support for the programme is already high. Britain has pledged $£ 100$ million to grid computing. John Taylor, director general of the UK research councils, told research ministers in Lisbon last month that the grid represented a fundamental shift in computing, and would allow global teams of scientists to access large-scale computing resources and data collections distributed across many institutions and countries.

A $\$ 500$ million five-year grid effort is already under way in the United States, involving 50 research centres coordinated by the National Computational Science Alliance.

Preliminary discussions suggest that Europe's grid effort is likely to "match or exceed" that of the United States, says Robin Middleton, a scientist at the UK Rutherford Appleton Laboratory and the PPARC representative of the CERN proposal.

The CERN project is seen as a forerunner for similar proposals from other disciplines with similar computing needs, such as bioinformatics and astronomy.

\section{Congo war increases threat to bonobo research}

\section{Asako Saegusa, Tokyo}

Future research on the rarest and leastknown species of great ape is being seriously endangered by the intensifying civil war in the Democratic Republic of Congo, according to leading primate researchers.

They believe that threats to the wild population of bonobos (Pan paniscus), or pygmy chimpanzees, could jeopardize ongoing studies of their life histories and evolution. Work following up suggestions that bonobos might be useful in research on the origins of AIDS could also be harmed.

Wild bonobos are found only in Congo. Their population was estimated at around 10,000 in 1996, but is thought to have halved over the past few years as a result of habitat loss and an increase in hunting for their meat. The recent outbreak of armed conflict within core bonobo habitats is believed to have reduced their numbers still further.

"Ongoing [great ape] conservation programmes are subject to severe disruption all too often," says Richard Wrangham, a Harvard University primatologist. He notes that more than two-thirds of 23 protected areas containing great apes have been disturbed by military conflicts during the past ten years.

"Since bonobos were the last of the great apes to be studied, their life history is yet to be understood," says Takayoshi Kano, a primate researcher at Kyoto University, who launched a pioneering study on wild bono-

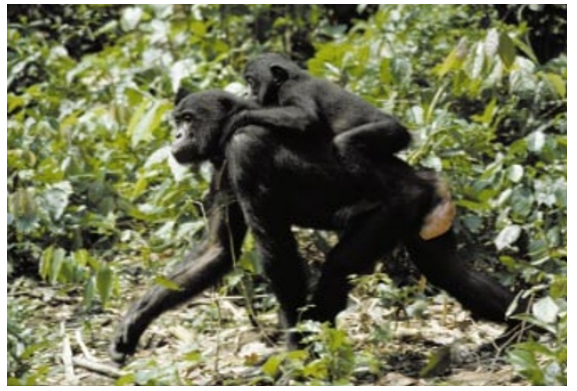

Bonobos: endangered on more than one front.

bos in 1973. "Even if bonobos do survive the ravages of war, their population will have been disrupted, and beginning a fresh study on a different group would be an unthinkably daunting task."

As human contact with bonobos increases with accelerated hunting - which often involves primitive butchery - there is growing concern over the risks that the apes could transmit disease to humans. Particularly in the light of the recent discovery that primate retroviruses can be transmitted to humans relatively easily through hunting.

Recent findings that HIV-1 might have arisen from chimpanzees in central Africa have triggered interest in bonobos as a research subject, although SIV - the ape equivalent of HIV - has not been detected from the handful of bonobo samples that have been tested so far.

\section{$\mathrm{NIH}$ takes charge of chimps infected in experiments}

\section{Paul Smaglik, Washington}

The US National Institutes of Health (NIH) has taken over responsibility for $\mathbf{2 8 8}$ chimpanzees infected with HIV and hepatitis $\mathrm{C}$ as a result of research projects. The chimps are currently housed at the Coulston Foundation in Alamogordo, New Mexico.

Coulston, a private research laboratory, has been criticized by animal-rights groups for the conditions under which its animals are kept, and has been chastised by the US Department of Agriculture (USDA). But it is still in the running to bid for contracts to care for the animals.

Coulston, which was founded by Frederick Coulston, lost two such contracts last year after USDA investigations ruled that the facility had violated the Animal Welfare Act. USDA inspectors reported that Coulston's chimp housing was dirty, infested and poorly ventilated. According to

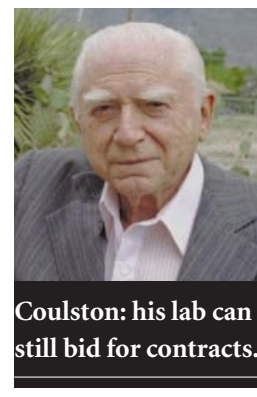

the department, these conditions contributed to the deaths of three chimps.

The loss of the contracts - worth $\$ 10$ million over six years - put the Coulston lab in financial trouble and cast doubts over its

future (see Nature 398, 644; 1999). Its financial situation "has become very critical", says John Strandberg, NIH director of comparative medicine.

But a successful bid by Coulston could help keep the organization solvent. Bids will begin in June and will undergo peer review. Don McKinney, a spokesman for Coulston, declines to comment on whether it will bid for the contract. However, he says he is "enthused" that NIH is supporting care of the animals.

Most of the 288 chimps, which represent about half of Coulston's total chimp population, are housed at Alamogordo's Holloman Air Force Base, leased by Coulston. Of the 288,25 remain in active clinical trials. The foundation will still own around 300 other chimps.

Strandberg says Coulston deserves to bid for the chimps' care, since conditions there have improved. "They have been intensively monitored," Strandberg says. "They've responded to many of the issues."

The California group In Defense of Animals, which opposes animal research, disagrees. It wants the permanent retirement of all chimpanzees used in government-sponsored research and opposes any involvement in their care by Coulston. “The NIH's deal does not accomplish either of these pressing goals," says Elliot Katz, the group's president. 